\title{
AUTOESTIMA, AUTOIMAGEM E CONSTITUIÇÃO DA IDENTIDADE: UM ESTUDO COM GRADUANDOS DE PSICOLOGIA
}

\author{
SELF-ESTEEM, SELF-IMAGE AND IDENTITY CONSTRUCTION: \\ STUDY WITH PSYCHOLOGY'S UNDERGRADUATE STUDENTS
}

\author{
Helena Serafim de Vasconcelos \\ Psicóloga clínica/ambulatorial pelo Instituto de Oncologia da Bahia. Lauro de Freitas, Bahia, Brasil. \\ helena.sv29@gmail.com
}

\begin{abstract}
RESUMO I Esta pesquisa objetivou identificar as possíveis transformações percebidas por estudantes de Psicologia ao longo do curso e o impacto destas na autoestima e na autoimagem. Com um desenho híbrido, realizou-se inicialmente um estudo-piloto de corte transversal analítico, no qual foram encaminhados questionários semiestruturados a 235 estudantes de psicologia de uma instituição sem fins lucrativos da Bahia, por e-mail. Os resultados identificaram um perfil sócio demográfico consonante com a literatura, sendo a maioria de mulheres, entre $16 \mathrm{e}$ 21 anos de idade, heterossexual e autodenominada parda. Na amostra, 73,81\% afirmaram melhora na autoestima. Num segundo momento, realizou-se um estudo complementar qualitativo, no qual, através de entrevistas individuais com alunos do último ano, verificou-se que a maioria afirmava percepção de mudança positiva na autoestima e na autoimagem, relacionando-as à experiência do curso de Psicologia. Houve também relatos de amadurecimento pessoal e empoderamento na realização das atividades práticas propostas nas diferentes áreas de estágio curricular, além da formação de identidades profissionais a partir dessas experiências e do curso de graduação.
\end{abstract}

Palavras-chave: estudante universitário, psicologia, identidade, autoestima, autoimagem.

\begin{abstract}
This research aimed to identify the possible transformations perceived by students of Psychology throughout the course and their impact on self - esteem and self - image. With a hybrid design, a pilot cross-sectional analytical study was carried out, in which semi-structured questionnaires were sent to 235 psychology students from a non-profit institution in Bahia, by e-mail. The results identified a sociodemographic profile consonant with the literature, being composed by women, between 16 and 21 years of age, heterosexual and self-referenced as brown the majority of this research population. In the sample, $73.81 \%$ affirmed an improvement in selfesteem. Second, a qualitative complementary study was carried out in which, through individual interviews with seniors, it was verified that the majority affirmed a perception of positive change in self-esteem and selfimage, relating them to the experience of the course of study Psychology. There were also reports of personal maturation and empowerment in the accomplishment of the practical work during the internship, that, in addition with the undergraduate course experiences', leaded to the formation of professional identities.
\end{abstract}

Keywords: undergraduate student, psychology, identity, self-steem, self-image. 


\section{INTRODUÇÃO}

$O$ ingresso no ensino superior coloca $\circ$ jovem de frente com uma nova realidade, que the demanda diferentes formas de enfrentamento da experiência de uma educação de adultos, com novos códigos e linguagens específicas (Coulon, 2008). Apropriarse dessa nova realidade pode se constituir numa experiência de desenvolvimento de autonomia ou de sofrimento. Espera-se que a vivência do ensino superior produza um deslocamento da posição de sujeito frente à nova realidade em que está inserido para que novas identidades sejam construídas, permitindo maior adaptabilidade desse sujeito ao processo de formação universitária (Hall, 2011; Coulon, 2008).

O espaço acadêmico não se configura apenas como um ambiente de continuação do processo de educação formal, mas num espaço de convivência, responsável por grande parte do processo de socialização do estudante (Mosquera et al, 2006), um espaço de produção subjetiva. A experiência de formação acadêmica contempla simultaneamente os processos de socialização cultural, de construção de humanidade (Bock, 2004) e de produções sobre si. Nessa perspectiva, revela-se como um campo passível de investigação a respeito das transformações identitárias vividas pelos estudantes.

A autoimagem e a autoestima, elementos constitutivos da construção identitária, são aspectos da subjetividade que estão presentes no processo de formação universitária. Mosquera et al. (2006) afirmam que estes aspectos são componentes chaves tanto na constituição, como para a compreensão do Eu e na forma como os indivíduos interagem entre si, a partir das diferentes perspectivas que tenham sobre si mesmos. Os autores identificam que, entre os estudantes universitários situados na etapa de transição da adolescência para a vida adulta, podese observar uma maior vulnerabilidade psíquica, visto que ainda estão em processo de aprendizado sobre si, sobre seus valores e suas interações com outros e com o mundo (Mosquera et al., 2006). Entretanto, para além desta formação subjetiva individual, os estudantes de Psicologia necessitam apreender a subjetividade também como objeto de estudo de sua prática, formulando uma nova identidade, a qual estará relacionada ao campo social do trabalho, no qual, futuramente, estará inserido (Woodward, 2014), aqui denominada ocupacional.

Os termos subjetividade e identidade apresentam uma considerável sobreposição de seus conceitos, permitindo que sejam inter-relacionados, de acordo com Woodward (2014) em seus estudos. Para a autora, subjetividade refere-se à forma como o indivíduo compreende a si mesmo, envolvendo os sentimentos e pensamentos do sujeito. A identidade sugere as posições assumidas pelo sujeito no contexto social onde a subjetividade é vivida, a partir das interações feitas através da linguagem e da cultura (Woodward, 2014). É importante destacar que, delimitar tal objeto traz à tona a condição mutável desses sujeitos submetidos a processos de transformação incessante em prol de sua construção. As transformações ou mudanças vivenciadas pelo sujeito em seu processo formativo não ocorrem de forma espontânea, como a metamorfose da lagarta ou apenas sob condições ideais de temperatura e pressão. Ocorrem, de fato, pelas interações estabelecidas com os outros, nos encontros que se realizam com a sociedade, com a cultura, ultrapassando as características biológicas (Bock, 2004). Portanto, para além da capacidade inata de transformar-se como ser vivo, o ser humano eleva sua potência de construção de si a partir das interações sociais, qualificando sua humanidade.

O homem e a mulher só ascendem à humanidade a partir da construção de um conjunto de aptidões e habilidades que os definem, a partir da transmissão do que já se construiu sobre a sua existência e vivência no mundo das gerações precedentes (Bock, 2004). É neste momento em que a cultura, "sistemas ou códigos de significado que dão sentido às nossas ações" (Hall, 1997), integra tal processo, marcando a singularidade de cada ser humano no contexto sócio histórico em que se encontra. As interações sociais estabelecidas permitem que a comunicação se realize, bem como $\circ$ estabelecimento das relações interpessoais. Assim, pode-se afirmar que situações que impliquem o convívio com outros indivíduos mostram-se como potentes oportunidades 
de crescimento e desenvolvimento pessoal pelas trocas estabelecidas nestes encontros.

A Teoria dos Estudos Culturais permite discutir a formação da identidade a partir de duas perspectivas distintas e concorrentes: a essencialista e a não essencialista. A primeira define que existe um conjunto cristalino e autêntico de características que todos aqueles que pertençam a determinado grupo partilham e que não se modificam ao longo da história. Já a segunda, foca nas diferenças e nas semelhanças entre os indivíduos que componham certo grupo e deste para com outros grupos, pressupõe formas mutáveis de definição do que seja ser parte deste grupo com o passar do tempo. Nota-se, portanto, que esta última concebe que o ser humano seja capaz de assumir diversas posições identitárias tanto ao longo da própria vida como a partir do contexto social e cultural em que se encontre, afirmando a identidade a partir de um conceito relacional (Woodward, 2014).

A perspectiva não essencialista, proposta pelos Estudos Culturais (Woodward, 2014; Hall, 2011) circunscreve o campo teórico desse estudo, permitindo perceber os conceitos de autoestima a partir da contextualização deste aspecto subjetivo na história dos sujeitos:
"Pesquisar sobre autoestima requer situar determinado sujeito em um contexto afetivo que envolva a família ou as pessoas significativas, desde suas primeiras relações até outras situações constitutivas, como (...) a escola e o trabalho, nos diferentes momentos do ciclo vital e do espaço sociocultural"

(Jeronimo \& Gonçalves, 2008, p. 195).

A autoestima é circunscrita pela literatura como a avaliação que o indivíduo faz de si mesmo, atribuindo um valor de si, sendo considerado um importante indicador de saúde mental (Assis \& Avanci, 2004; Mosquera \& Stobäus, 2006; Bandeira \& Hutz, 2010). De acordo com Bandeira (2005), a autoestima está diretamente conectada ao desempenho na interação social, o que se confirma também com outros autores (Mosquera et al, 2006; Bandeira \& Hutz, 2010).

As concepções aqui apresentadas sobre a autoimagem, também se organizam a partir dessa perspectiva dinâmica, de múltiplas identidades. Configura-se como uma organização interna de si mesmo, composta por dados de realidade e dados subjetivos de autopercepção (Mosquera \& Stobäus, 2006). Assim, compreende-se a autoestima e a autoimagem como características da subjetividade humana que apresentam um papel importante na forma como uma pessoa se relaciona com outras e consigo mesma, na constituição identitária propriamente dita, que vão, simultaneamente, organizar-se em torno do conceito de identidade aqui trabalhado, como apresentado no diagrama da Figura 01.

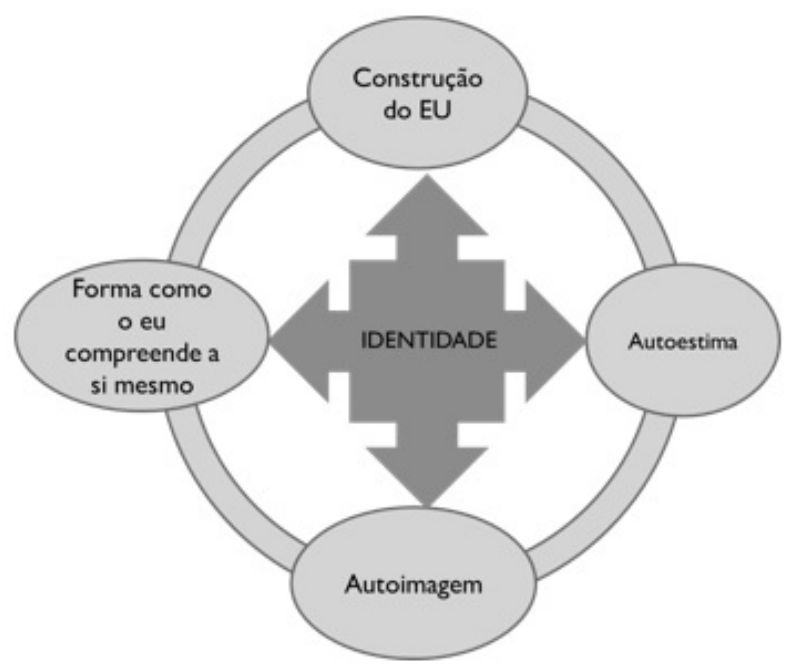

Figura 1. Elementos conectados ao conceito de Identidade 
Esse estudo dirige o seu olhar para a relação existente entre autoestima e autoimagem e o fazer em psicologia, discutindo a partir disso a construção da identidade do psicólogo. É necessário destacar que o fazer do psicólogo realiza-se exatamente no encontro com o outro (outros) e nos vínculos que se constituem nessas relações, perspectiva que põe em evidência a subjetividade do próprio psicólogo nesse campo dialógico que se constitui.

Nessa perspectiva, ○ espaço de formação universitário pode ser compreendido como um dos espaços sociais de encontro e convívio constante entre pessoas. Apresenta, como peculiaridade, o fato de que, além de ser destinada à produção de conhecimento, $\circ$ seu processo mobiliza de forma direta ou indireta as questões referentes à subjetividade (Mosquera et al, 2006), causando consequente impacto na autoestima desses sujeitos. É na universidade que os estudantes buscam encontrar, para além da formação de uma identidade profissional, crescimento e ter realização pessoal (Pachane citado por lgue, 2008).

Segundo Papalia ef al (2013), a própria exposição ao ambiente educacional universitário se constitui, em termos cognitivos e sociais, como uma experiência de amadurecimento. É um espaço composto majoritariamente por jovens, que oferece a possibilidade de problematizar verdades e de construir uma identidade ocupacional. Tais processos se desenvolveriam tanto a partir da aquisição de conteúdos técnicos, como pelo reconhecimento da complexidade existente no mundo dos adultos.

Assim, pode-se afirmar que a vivência universitária é reconhecida como uma experiência mobilizadora em distintos aspectos, pois envolve cobranças, atitudes, capacidade de adaptação às novas demandas de espaço, autonomia e relacionamentos (Coulon, 2008; Cunha \& Carrilho, 2005). Estudos citados por lto (2007) e Bandeira (2005) sugerem que autoestima positiva indica uma percepção de maior suporte social e de satisfação acadêmica, - que contribui positivamente para o desempenho social e a capacidade de adaptação, bem como para uma percepção menor de solidão. Segundo Briggs (citado por Jeronimo \& Gonçalves, 2008), pessoas que apresentem a autoestima elevada são capazes de conseguir superar adversidades, definir metas para si mesmas, ao passo em que também conseguem agir em prol do bem-estar do próximo.

Nesse estudo, o psicólogo está compreendido como uma profissão de saúde, tendo sua prática associada aos novos modos de se pensar saúde, como um campo de atuação complexo e multifacetado, que envolve aspectos socioculturais, históricos e subjetivos, afastado do modelo biomédico vigente, de acordo com Daltro et al (2012). Assim, reconhece-se que a formação acadêmica deve estar voltada para capacitá-lo para atuar como promotor de saúde e qualidade de vida, independente dos contextos em que esteja inserido. Para tanto, é necessário considerar o desenvolvimento do empoderamento, - qual é uma concepção que está no núcleo filosófico da própria proposta de promoção à saúde. $O$ empoderamento ou empowerment referese ao investimento nas possibilidades individuais e coletivas de aprendizado, ao reconhecimento da capacidade de cada sujeito viver a vida em suas distintas etapas, lidando com as possibilidades e limitações impostas por eventuais enfermidades. (Carvalho \& Gastaldo, 2008).

Dessa forma, esse estudo pressupõe a existência de uma relação entre autoestima elevada e empoderamento individual, o qual se configura como um importante objetivo para a formação em psicologia. Ao desenvolvê-lo, os sujeitos contarão com um maior sentimento de controle sobre a forma como lidam com a própria vida, possibilitando ainda o desenvolvimento de recursos que lhes permitam agir com maior autonomia frente às adversidades (Kleba \& Wendausen, 2009). Para Horochovski e Meirelles (2007), o empoderamento individual sofre influência de aspectos subjetivos como a autoestima, só podendo ser alcançado a partir da garantia de recursos de poder (como a autoestima e o sentimento de devir).

Esse estudo considera que uma autoestima e autoimagem positivas podem favorecer ao estudante de Psicologia um maior empoderamento para manejar os distintos e complexos encontros demandados no cotidiano de sua futura prática profissional. Assim, propõe refletir sobre a relação existente entre esses elementos e 0 processo de formação acadêmica. Nessa perspectiva, investiga a percepção de estudantes sobre as mudanças 
na autoestima e na autoimagem vivenciadas na experiência da graduação em psicologia.

\section{MÉTODO}

Trata-se de um estudo híbrido, dividido em duas etapas. A primeira etapa constitui-se por uma pesquisa-piloto de corte transversal que permitiu realizar um mapeamento sócio demográfico sobre as percepções de estudantes sobre as alterações vividas na sua autoestima frente à exposição ao curso. A população de base foram todos os 235 estudantes de um curso de psicologia de uma instituição privada sem fins lucrativos de ensino superior no estado da Bahia, no Brasil. O instrumento de avaliação foi um questionário semiestruturado contendo 70 questões que envolvem dados sócio demográficos, informações sobre $\circ$ percurso acadêmico e referentes às percepções sobre 0 processo formativo.

Os dados foram coletados entre março e abril de 2013, por via eletrônica. O questionário foi enviado, com o apoio do software Survey Monkey, para os estudantes pelo e-mail institucional. Estes foram convidados a participar da pesquisa em suas respectivas salas de aula e informados a respeito dos objetivos e do envio do e-mail com o link do questionário para que fossem encorajados a participar do estudo. A população de estudo foi de 84 estudantes que aceitaram participar da pesquisa ao assinarem $\circ$ Termo de Esclarecimento Livre e Esclarecido - T.C.L.E. por via eletrônica.

As frequências de respostas foram identificadas com - apoio do pacote estatístico SPSS 14 e cruzando variáveis sócio demográficas com as questões referentes aos processos de transformações ocorridas ao longo do curso com relação à autoestima, relação com o próprio corpo e saúde mental e a significância estatística avaliada com o uso do teste de $\mathrm{X}^{2}$.

A segunda etapa ocorreu como aprofundamento da primeira, constituindo-se de uma pesquisa de campo complementar exploratória de natureza qualitativa. Estruturou-se a partir de entrevista semiestruturada individual de oito estudantes (visto a dificuldade de adesão e resposta ao convite da pesquisa) que cursassem o $9^{\circ}$ ou $10^{\circ}$ semestre de Psicologia (quatro de cada semestre), escolhidos de forma aleatória, por sorteio, matriculados no componente curricular Estágio Específico I ou II. Foram escolhidos alunos neste período, pois permitiria centrar o estudo junto às percepções de alunos que já estivessem no final da formação e que pudessem abordá-la a partir da experiência de estágio na área de interesse profissional. Optou-se por ter dois entrevistados representantes cada uma das quatro áreas de estágio disponibilizadas pelo curso (saúde mental, psicologia hospitalar, psicologia organizacional e ambulatório) nesse ano, a fim de comparar as respostas nos diversos campos de inserção prática do psicólogo e assim perceber possíveis diferenças ou semelhanças que este dado pudesse influenciar na percepção da autoestima e da autoimagem, sem perder de vista que estariam englobadas enquanto áreas de promoção de saúde. $O$ roteiro utilizado era composto por quatro perguntas, sendo duas referentes à compreensão do conceito de autoestima e autoimagem que cada um detinha e outras duas referentes a se fora percebida alguma mudança nestes aspectos e de que forma isso teria acontecido no decorrer do curso.

As entrevistas foram realizadas entre os meses de março e abril e novembro e dezembro de 2014, no Serviço de Psicologia da dada instituição, para buscar garantir maior conforto e privacidade, considerando que a pesquisa visava uma maior exposição de dados subjetivos dos sujeitos. Foram considerados como critérios de inclusão que os alunos estivessem cursando $\circ 9^{\circ}$ ou $10^{\circ}$ semestre na época em que foram feitas as entrevistas, que aceitassem participar do estudo assinando o TCLE. Como critérios de exclusão qualquer aluno que não estivesse neste período do curso na referida faculdade, considerando que não teriam uma vivência suficientemente avançada do curso.

Para realizar a análise destas respostas, foi utilizado o método de análise de sentido descrito por Minayo (2010), a partir das categorias identificadas. Admitiu-se como risco que os estudantes pudessem sentir-se desconfortáveis, constrangidos ou mesmo sensibilizados ao responderem às perguntas do questionário ou às entrevistas, ao que foram 
esclarecidos de que poderiam interromper a qualquer momento a participação e de que poderiam ser atendidos pela orientadora da pesquisa. No entanto, com relação aos benefícios, seria possível contribuir para a ampliação do campo de discussão acerca da construção da identidade dos futuros profissionais psicólogos, bem como servir de fonte de análise sobre a vivência do curso na atualidade. Oestudo foi aprovado pelo Comitê de Ética e Pesquisa sob o número do CAAE 03670812.7.0000.5544. Todos os participantes assinaram o TCLE eletronicamente (na primeira etapa) e pessoalmente (na segunda etapa) de forma a estarem protegidos.

\section{RESULTADOS E DISCUSSÕES}

Esse estudo analisou inicialmente um grupo de 84 estudantes que responderam às questões referentes à percepção de melhora ou mudança na autoestima e autoimagem. Entre os respondentes, 65,4\% (50) têm entre 16 e 21 anos, 34,5\% (27) têm entre 22 e 33 anos e 8,3\% (7) tem 34 anos ou mais. Dentre eles, $91,7 \%$ (77) são do sexo feminino e $8,3 \%$ (7) são do sexo masculino. Em relação à cor autodeclarada $53,6 \%$ (44) afirmaram ser pardos, 29,2\% (24) brancos, $17,0 \%$ (14) se consideram pretos. No que se refere à orientação sexual $88,0 \%$ (74) se afirmaram heterossexual, $3,5 \%$ (3) estudantes afirmaram ser homossexual e 8,3\% (7) bissexual. Estes dados podem ser observados na Tabela 1.

Tabela 01. Distribuição de frequência de dados sócio demográficos entre os estudantes de psicologia

\begin{tabular}{|c|c|c|c|}
\hline & VARIÁVEL & $\begin{array}{l}\mathrm{N} \\
84\end{array}$ & $\%$ \\
\hline \multirow[t]{3}{*}{ FAIXA ETÁRIA } & 16 a 21 anos & 50 & 59,5 \\
\hline & 22 a 33 anos & 27 & 32,1 \\
\hline & 34 anos ou mais & 7 & 8,3 \\
\hline \multirow[t]{2}{*}{ SEXO } & Masculino & 7 & 8,3 \\
\hline & Feminino & 77 & 91,6 \\
\hline \multirow[t]{3}{*}{$\operatorname{COR}(\mathrm{N}=82)^{*}$} & Branca & 24 & 29,2 \\
\hline & Preta & 14 & 17,0 \\
\hline & Parda & 44 & 53,6 \\
\hline \multirow[t]{3}{*}{ ORIENTAÇÃO SEXUAL } & Heterossexual & 74 & 88,0 \\
\hline & Homossexual & 3 & 3,4 \\
\hline & Bissexual & 7 & 8,3 \\
\hline
\end{tabular}

*o número de respostas a este quesito foi inferior ao número de respostas às demais perguntas

Os resultados identificam um perfil sócio demográfico consonante com os estudos de Yamamoto et al (2011) referente à população brasileira de estudantes de Psicologia. Composta por uma maioria de mulheres
(91,6\% - 77), com idade entre 16 e 21 anos $(65,4 \%$ - 50). A faixa etária dos estudantes que também corresponde à população nacional configura um perfil populacional de adolescentes vivenciando 
um processo de entrada para a vida adulta. Cunha e Carrilho (2005) destacam que este pode ser considerado como um fator de vulnerabilidade para este momento na vida do jovem, pois é também nesta fase em que se aprende a lidar com os desafios que a vida adulta impõe. Desta maneira, caracterizam-na como uma fase marcada por transformações em nível de identidade e do desenvolvimento vocacional.
A Tabela 2 apresenta $\circ$ cruzamento da variável "faixa etária" com a percepção dos estudantes sobre a "melhora" ou "não melhora" da autoestima. A melhora foi indicada por $70 \%$ (35) e $74 \%$ (20) dos estudantes mais jovens (menos de 34 anos), sendo apontada por menos de $50 \%$ entre os estudantes com mais de 34 anos. Os demais dados coletados na etapa quantitativa foram trabalhados e discutidos em um estudo a parte, no qual o aspecto da autoestima foi destacado para discussão central.

Tabela 02. Frequência de respostas sobre percepção de mudança na autoestima dos estudantes de acordo com a faixa etária

\begin{tabular}{lcccccc}
\hline IDADE & $16 \mathrm{a}$ & & $22 \mathrm{a}$ & & 34 ou \\
& 21 & & 33 & & mais & \\
\hline AUTOESTIMA & $\mathrm{N}$ & $\%$ & $\mathrm{~N}$ & $\%$ & $\mathrm{~N}$ & $\%$ \\
Melhorou & 35 & 70,0 & 20 & 74,0 & 3 & 42,8 \\
Não melhorou & 15 & 30,0 & 7 & 25,9 & 4 & 57,1 \\
\hline
\end{tabular}

Foi possível constatar já nesta primeira etapa do estudo que os estudantes apresentaram uma percepção de mudança em sua autoestima, na medida em que referiram melhora ou piora neste aspecto ao longo do curso. Este fato pode estar relacionado ao perfil majoritariamente adolescente, sendo que Mosquera et al (2006), afirmam a necessidade de atentar para a vulnerabilidade do indivíduo neste processo de formação identitária ainda em vias de consolidação (Assis \& Avanci 2004; Mosquera \& Stobäus, 2006; Bandeira \& Hutz, 2010; Bock, 2004; Igue et al, 2008; Cunha \& Carrilho, 2005). Os adolescentes estão mais sujeitos a sofrer modificações nos aspectos da autoestima e autoimagem, os quais estão diretamente relacionados a ela. Dessa forma, observa-se que os resultados demonstrados na Tabela 02 parecem confirmar o que a literatura aponta, porém não alcançam sozinhos a complexidade do tema abordado, nem mesmo afirmar o processo de transformação indicado. É necessário, portanto, fazer alguns destaques com relação a este dado.

Assim, a partir da coleta de dados realizada pela pesquisa de corte transversal, observou-se a necessidade de buscar melhor aprofundar as questões relacionadas à autoestima e autoimagem, visto $\circ$ seu importante papel de mapeamento das informações e inferências realizadas acima dentro do processo final da pesquisa. Assim, a etapa qualitativa exploratória apresentou-se como fundamental para compreender e refletir sobre as respostas que afirmavam melhora na etapa anterior.

A seguir, estão descritos os resultados obtidos a partir das entrevistas realizadas posteriormente, dividas entre as categorias observadas a partir da análise de sentido proposta por Minayo (2010) para definir os conceitos de autoestima e autoimagem e as mudanças, se observadas, sobre tais aspectos subjetivos.

\section{Concepções sobre autoestima e autoimagem Interioridade}

Nas respostas encontradas a partir das entrevistas individuais, observou-se que a autoestima está referida a partir da noção de interioridade, do sentir sobre si. A categoria interioridade está referida a partir de três núcleos de sentido: emerge como auto avalição (auto percepção), conforme a fala do Estudante 03 "[...] Autoestima envolve a avaliação do indivíduo sobre ele mesmo acerca de como é que ele se sente [...]", e do Estudante 06 "[...] julgamento ou avaliação sobre si mesmo, tá? No caso, você avaliando... Quanto você vale [...]" como sentimento de bem-estar pessoal e físico, de acordo 
com ○ Estudante 07, “[...] Autoestima... É algo que diz respeito a você e o que você sente [...] tá muito ligada ao corpo;" e relacionada à influência social e ambiental, apontado pelo Estudante 08 "[...] Bom, autoestima para mim, nesse momento, é você sentir-se bem consigo mesmo e com o meio o qual você vive." Sentidos esses que marcam a singularidade de cada um, mas também apresentavam semelhanças entre si.

A compreensão apresentada pelos estudantes corrobora com o ponto de vista teórico de que se trata de um conteúdo pertencente ao campo subjetivo, que pode ser passível de interferências de ordem externa, sendo necessária sua contextualização no tempo e espaço em que o sujeito está inserido (Jeronimo \& Gonçalves, 2008).

\section{Diálogo entre percepções}

Essa categoria aponta para o núcleo de sentido identificado como diálogo percepção de si dialogada com a percepção do outro, possibilitando inferir uma representação imagética e subjetiva simultânea diante do mundo a partir destes dados, como ocorre nas respostas:

"Autoimagem pra mim é como você se percebe como você se vê... Em imagem mesmo [...] que você acha que representa pro mundo... E pra você mesmo"

(Estudante 07)

"Autoimagem pra mim está relacionado a sua imagem física a aparência física [...] de uma forma mais geral como você se apresenta não só levando em consideração a imagem corporal mas toda a sua posição no mundo..." (Estudante 08)

Autoimagem também tem a ver com o olhar, mas com o nosso olhar a gente nos vendo a partir de como a gente acha que o outro nos vê também eu acho que a autoimagem tem esse.... Essa troca esse diálogo entre o seu olhar e o olhar do outro

(Estudante 04)

Essa concepção de autoimagem que emerge nas narrativas dos estudantes é compatível com a noção trabalhada por Mosquera e Stobäus (2006) de que, é uma organização interna de si mesmo, composta por dados de realidade e dados subjetivos de auto percepção. As respostas referentes a autoimagem se colocam como campo para analisar a produção de identidade, na medida em que é percebida, pelos próprios estudantes, como aspecto que interfere no posicionamento diante do outro, assim como é afirmado por Woodward (2014).

\section{Mudanças na autoestima}

\section{Mudanças introspectivas e Mudanças nas Relações Interpessoais}

Dentre os oito estudantes entrevistados, seis afirmam perceber mudanças na autoestima frente à exposição ao curso. Na análise dos resultados, essas duas categorias de resposta foram identificadas como campos onde as mudanças se processaram identificadas pelos núcleos introspectivo e interpessoal. Esse impacto está referido, pelos estudantes, como positivo na autoestima:

Me sinto como se fosse mais importante [...] tendo maior valor para a sociedade (Estudante 06);

[...] comecei a me perceber mais durante o curso e eu acho que isso me ajuda... Profissionalmente, mas me ajuda muito como pessoa mesmo pra minha vida no geral, não só como psicóloga [...] (Estudante 04);

[...] minha autoestima se elevou bastante [...]é um momento ideal, minha autoestima está boa[...]

(Estudante 01).

Considerando a necessidade de que a formação universitária busque garantir a capacidade de atuação do psicólogo enquanto promotor de saúde em distintos cenários em que esteja inserido, tornase válido ressaltar a importância da percepção positiva sobre a própria autoestima como indicada pelos estudantes. De acordo com os estudos citados por Ito (2007) e Bandeira (2005), uma percepção de maior suporte social e de satisfação acadêmica, contribuindo positivamente para o desempenho social e a capacidade de adaptação, bem como para uma percepção menor de solidão. Da mesma forma, apresentar a autoestima elevada também indica uma maior capacidade de conseguir superar adversidades, definir metas para si mesmos, ao 
passo em que também conseguem agir em prol do bem-estar do próximo (Briggs citado por Jeronimo \& Gonçalves, 2008), características que também são valorosas para um desempenho profissional adaptável ao contexto, assim como para o manejo de um objeto tão complexo como a subjetividade.

\section{Mudança na autoimagem}

\section{Olhar para si e exposição}

A percepção dessa mudança esteve indicada por sete estudantes que apresentaram uma relação direta com a experiência do curso. É importante destacar que apenas um único estudante não reconheceu mudanças nessa dimensão, nem também na autoestima, pois reconheceu em seu discurso que a forma como conceitua estes conceitos não lhe permite reconhecer uma mudança nesses aspectos. Entre os que afirmaram a mudança ficou identificado que a exposição ao curso de Psicologia favoreceu a experiência de transformação. Assim, reconheceu-se a influência disso em dois núcleos de sentido denominados percepção sobre a identidade pessoal e exposição ao olhar do outro:

[...] eu acho que é isso que eu mudei [...] tanto a minha imagem corporal quanto a minha forma de me colocar, a minha forma de se vestir e a minha forma de interagir com o mundo. (Estudante 08)

[...] logo no começo, quando eu me inseri na faculdade, a minha autoimagem era de uma...

De uma estudante recém-formada do Ensino Médio [...] e hoje em dia eu já me percebo como uma profissional também, então tudo isso acaba agregando também na, na autoimagem, né? [...]

(Estudante 03)

O conceito de autoestima está ancorado na autoimagem, onde é possível identificar as mudanças vividas pelos sujeitos na construção de uma identidade profissional. De acordo com Hall (2011), as vivências da contemporaneidade implicam numa compreensão de sujeito que se desloca entre múltiplas identidades, considerando que as experiências do convício social implicam numa necessidade de produção de novas subjetividades/ identidades. Fato este que também é corroborado por Woodward (2014), na medida em que reconhece em seu estudo que não é possível se pensar numa identidade fixa e imutável ao longo da vida, mas sim num sujeito que se transforma ao ser afetado pela cultura e linguagem que o circunscreva. A formação em psicologia é percebida pelos estudantes como um território propício para o desenvolvimento de novas produções identitárias, não sendo observada nas respostas qualquer percepção negativa de mudança.

\section{Efeitos da exposição ao curso - mudanças produzidas}

Entre os entrevistados, emergiram referências específicas sobre a experiência do curso, ressaltando-o como um lugar de inserção social, de experiência de desenvolvimento e amadurecimento pessoal e subjetivo, bem como um processo desafiador, o que implicaria na questão da autoestima. É importante atentar que, mesmo os alunos que não identificaram mudança em sua autoestima ou autoimagem diante da exposição ao curso, relataram que o curso se configurou como uma experiência mobilizadora e transformadora no âmbito pessoal.

[...] mudanças promovidas pela formação de psicologia são muito mais de ordem subjetiva mesmo, né? De amadurecimento enquanto pessoa [...];

(Estudante 05)

[...] é um curso muito difícil, né? Um curso que mexe com você [...] de repente do nada você iá começa a se fazer questionamentos existenciais mesmo, com relação a você, com relação ao mundo que você vive [...] isso mexe muito com quem você é, com quem você pretende ser, né?[...] (Estudante 07)

Diante destes dados, o que se observa é que os alunos reafirmam que $\circ$ processo de formação acadêmica é uma experiência impactante, que impõe desafios e necessidade de adaptação a este espaço destinado a adultos (Coulon, 2008), que contribui para a inserção e interação social (Bock, 2004) e que é capaz de interferir subjetivamente em sua autoestima (Mosquera et al, 2006).

No específico da formação em psicologia, 
considera-se que a ocupação do lugar de um profissional psicólogo está representada a partir da uma responsabilidade ética a ser defendida e tornar-se "capaz de produzir benefícios aos outros profissionalmente" (Estudante 06), como afirma um dos sujeitos do estudo. Reflete uma percepção de empoderamento, de possibilidade de controle sobre a forma como lidam com a própria vida (Carvalho \& Gastaldo, 2008) com consequente abertura para poder cuidar do outro. Horochovski e Meirelles (2007) demarcam que uma percepção de maior empoderamento é influenciada por aspectos subjetivos, sendo alcançado a partir da garantia de recursos de poder, como alta autoestima, o que emerge nas respostas desse estudo.

Em três depoimentos o que emergiu como estratégia de suporte de enfrentamento dos sentimentos, das angústias, das dúvidas decorrentes do processo de autopercepção que se articulou com a experiência do curso foi a psicoterapia:

[...] acho que isso mexe com a questão de não tem como você ficar sem terapia [..] (Estudante 02)

É importante considerar que a autoestima é apontada pela literatura como um importante indicador de saúde mental, sendo, portanto, possível identificar que este aspecto tenha sido afetado também diante da exposição ao curso. No entanto, torna-se necessário atentar para os possíveis desdobramentos que o curso de Psicologia pode suscitar de forma mais aprofundada sobre este aspecto, o que não foi objetivado no presente estudo.

A alta autoestima possibilita maior capacidade de superação de adversidades, de definir metas para si mesmo, assim como de agir em prol do bemestar do próximo. No entanto, Mosquera e Stobäus (2006) afirmam que a avaliação da autoestima é oscilável e interfere de sobremaneira no julgamento que os estudantes fazem de si mesmos e na postura que assumem perante a vida (Assis \& Avanci, 2004). Tal fato deixa evidente a necessidade de discutir de forma mais avançada o lugar da dimensão subjetiva, da experiência acadêmica em psicologia, pois foi possível identificar com este estudo que os desafios da formação acadêmica reverberaram de forma positiva na própria identidade pessoal e profissional. Jeronimo \& Gonçalves (2008) ampliam essa perspectiva, destacando que a autoestima interfere tanto na identidade individual como na identidade coletiva, na medida em que tal aspecto se ergue a partir das "relações com grupos significativos presentes no espaço de vida dos sujeitos".

\section{CONSIDERAÇÕES FINAIS}

Nessa pesquisa, estudantes de psicologia afirmaram terem percebido mudanças na autoestima e na autoimagem ao longo do curso, que foram referidas a partir da percepção de melhora da autoestima, amadurecimento pessoal e conquista de uma identidade profissional.. Tanto a autoestima como a autoimagem são componentes da identidade que interferem na forma como o sujeito se relaciona com o mundo, sendo importante destacar que tal consideração identificada na literatura se confirma nos dados coletados junto aos estudantes de Psicologia. Mais do que isso, apontam para uma população que se reconhece como competente para atuar no mercado de trabalho e que considera a importância de seu exercício profissional junto à comunidade.

Para preparar os sujeitos para essa tarefa, de lidar com a subjetividade, o processo de formação em psicologia coloca em jogo o contato íntimo com a angústia, o sofrimento psíquico, a doença mental, a morte, o desamparo existencial, as contradições da natureza humana; além disso, apresenta objetos de estudo imateriais, que podem ser lidos e interpretados por diferentes pontos de vistas (Daltro, 2015). Todos esses elementos são frequentemente colocados de forma fragmentada, alocados em diferentes disciplinas que normalmente não conversam e, por vezes, até se desqualificam mutuamente e a exposição a esse universo simbólico pode criar condições para o desenvolvimento da autonomia e do amadurecimento pessoal, ou para a vulnerabilização psíquica desses sujeitos. Nesse estudo, a percepção de melhora na autoestima emergiu de forma majoritária entre os sujeitos da pesquisa dos últimos semestres, sendo indicativa de uma experiência de empoderamento de si, muito 
positiva ao enfrentamento das especificidades da prática de promoção de saúde em psicologia.

A autoestima e a autoimagem estão definidas como elementos fundamentais ao processo de formação do psicólogo e seu desenrolar individual ou grupal, interferindo na construção da própria identidade profissional. Além disso, é importante lembrar que a experiência do curso, bem como as percepções relatadas são parte das influências sofridas pelo estudante ao longo do seu processo formativo, sendo este estudo um apanhado inicial para permitir que as reflexões geradas semeiem novos estudos e superem os limites aqui enfrentados.

Dentre eles, a importância de um estudo longitudinal sobre processo de formação acadêmica, o que possibilitaria perceber o processo de transformação inicialmente sugerido, e da existência de instrumentos de avaliação validados sobre a experiência do curso de graduação aqui explorado. Observou -se, ainda, que os aspectos parecem abranger também outras questões e recursos que merecem ser melhor aprofundadas, como a saúde mental do estudante de psicologia e a experiência da psicoterapia. Logo, propõe-se que mais estudos sejam direcionados à formação em Psicologia, atentando-se para o impacto subjetivo que esta demonstra transpor para seus alunos, os quais futuramente se dedicarão a cuidar e transformar, pessoal e profissionalmente, ao longo da vida, esse objeto: a subjetividade humana.

\section{CONFLITOS DE INTERESSES}

Nenhum conflito financeiro, legal ou político envolvendo terceiros (governo, empresas e fundações privadas, etc.) foi declarado para nenhum aspecto do trabalho submetido (incluindo mas não limitandose a subvenções e financiamentos, conselho consultivo, desenho de estudo, preparação de manuscrito, análise estatística, etc).

\section{REFERÊNCIAS}

Assis, S. \& Avanci, J. (2004). Labirinto de espelhos: formação da auto-estima na infância e na adolescência. Rio de Janeiro: Fiocruz.
Bandeira, M., Quaglia, M.A.C., Bachetti, L. da S., Ferreira, T.L., \& Souza, G.G. de. (2005). Comportamento assertivo e sua relação com ansiedade, locus de controle e auto-estima em estudantes universitários. Estudos de Psicologia, 22(2), 111 -121. doi: 10.1590/ S0103-166X2005000200001

Bandeira, C. de M., \& Hutz, C.S. (2010). As implicações do bullying na auto-estima de adolescentes. Psicologia Escolar e Educacional, 14(1), 131-138. doi: 10.1590/ $\underline{\mathrm{S} 1413-85572010000100014}$

Bock, A.M.B. (2004). A perspectiva sócio-histórica de Leontiev e a crítica à naturalização da formação do ser humano: a adolescência em questão. Cadernos CEDES, 24(62), 26-43. doi: 10.1590/S010132622004000100003

Carvalho, S.R., \& Gastaldo, D. (2008). Promoção à saúde e empoderamento: uma reflexão a partir das perspectivas crítico-social pós-estruturalista. Ciência \& Saúde Coletiva, 13(Suppl. 2), 2029-2040. doi: $10.1590 /$ S1 1413-81232008000900007

Coulon, A (2008). A condição de estudante: a entrada na vida universitária. Salvador: EDUFBA.

Cunha, S.M., \& Carrilho, D.M. (2005). O processo de adaptação ao ensino superior e o rendimento acadêmico. Psicologia Escolar e Educacional, 9(2), 215 224. doi: $10.1590 /$ S1413-85572005000200004

Daltro, M.R. (2009). Contradições do Processo Formativo: um estudo sobre a saúde mental do estudante de medicina. Dissertação de Mestrado, Escola Bahiana de Medicina e Saúde Pública, Salvador, Brasil.

Daltro, M.R. Vilas Bôas, L.M. \& Danon, C.A.F. (2012). Uma proposta para a formação de psicólogos como profissionais de saúde na contemporaneidade. Revista Psicologia, Diversidade e Saúde, 1(1), 3-25.

Daltro, M.R. (2015). Um currículo para a formação do psicólogo como profissão de saúde. Tese de doutorado. Escola Bahiana de Medicina e Saúde Pública, Salvador, Brasil.

Dedios, M.C. (2010). Experiência emocional de un grupo de psicólogos en el trabajo con personas psicóticas. Dissertação, Universidade Católica del Peru, Peru, Lima.

Hall, S. (1997). A centralidade da cultura: notas sobre as revoluções culturais do nosso tempo.

Hall, S. (2011). A identidade cultural na pós-modernidade. Rio de Janeiro: DP\&A.

Horochovski, R.R. \& Meirelles, G. (2007). Problematizando o conceito de Empoderamento. Anais do II Seminário 
Nacional Movimentos Sociais. Florianópolis: UFSC.

Igue, E.A., Bariani, I.C.D., \& Milanesi, P.V.B. (2008). Vivência acadêmica e expectativas de universitários

ingressantes e concluintes. Psico-USF, 13(2), 155-164. doi: $10.1590 /$ S $1413-82712008000200003$

Ito, P. do C.P., Gobitta, M., \& Guzzo, R.S.L. (2007).

Temperamento, neuroticismo e auto-estima: estudo preliminar. Estudos de Psicologia, 24(2), 143-153. doi: 10.1590/S0103-166X2007000200001

Jerônimo, R.N.T., \& Gonçalves, T.M. (2008). O processo de apropriação do espaço e produção da subjetividade. Psicologia: Teoria e Pesquisa, 24(2), 195-200. doi: $10.1590 /$ S0102-37722008000200009

Kleba, M.E., \& Wendausen, A. (2009). Empoderamento: processo de fortalecimento dos sujeitos nos espaços de participação social e democratização política. Saúde e Sociedade, 18(4), 733-743. doi: 10.1590/S010412902009000400016

Minayo, M.C.S. (org.). (2010). Pesquisa Social: Teoria, Método e Criatividade. Petrópolis: Vozes.

Mosquera, J.J.M., Stobaus, C.D., Jesus, S.N., Hermínio, C.I, et al. (2006). Universidade: Auto-imagem, Auto-estima e Auto-realização. UNIrevista, 1(2).

Mosquera, J.J.M. \& STOBÄUS, C.D. (2006). Auto-Imagem, Auto-Estima e Auto-Realização: Qualidade de Vida na Universidade. Psicologia, Saúde \& Doenças, 7(1), 83-88.

Papalia D. \&, Olds S.W. (2013). Desenvolvimento humano. Porto Alegre: Artes Médicas Sul.

Woodward, K. (2014). Identidade e diferença: uma introdução teórica e conceitual. In: SILVA, T.T. (Org.) Identidade e diferença: A perspectiva dos Estudos Culturais. Petrópolis: Ed. Vozes.

Yamamoto, O.H., Falcão, J.T. da R., \& Seixas, P. de S.

(2011). Quem é o estudante de psicologia do Brasil? Avaliação Psicológica, 10(3), 209-232. 